\title{
How Old is Too Old? Observing A Centenarian After Primary PCI
}

\author{
(1) Çağlar Kaya, (i) Cafer Sadık Zorkun, () Ahmet Kenan Yalta
}

Trakya University Faculty of Medicine, Department of Cardiology, Edirne, Turkey

\begin{abstract}
Very elderly and frailty are two common risk factors for patients in the setting of acute myocardial infarction and its outcomes. Due to their exclusion from clinical research, follow-up data is inadequate in patients at their nineties and in centenarians. Timely performed percutaneous coronary intervention is the treatment of choice for acute myocardial infarction in very elderly. Unfortunately, patients in their
\end{abstract}

\section{Introduction}

Advanced age is an important risk factor for patients with acute coronary syndromes ${ }^{(1)}$. As population aged, centenarians or oldest old patients in the other term, became quite common in daily routine practice. Because of widely available modern catheter laboratory facilities, improved device technology and increased experience in interventional cardiology, primary percutaneous coronary intervention become the therapy of choice in very elderly with ST-segment elevation myocardial infarction ${ }^{(2)}$. late "90s or in nonagenarians, physicians or patients" relatives usually reject this approach for its invasive nature, multiple comorbidities, lack of larger meta-analysis and misbelief related fear. This report contains a history 98-year-old female presented within the first hour of an acute myocardial infarction and her two years' follow-up.

Keywords: Acute coronary syndrome, elderly, centenarian

Despite of reported complications, both radial and femoral approach can be performed successfully in these ages. On the other hand, regardless of all improvements for this safe and proven treatment option, patient's invasive procedure related fear, and their relative's opinion in these settings are the major barrier for timely performed percutaneous coronary interventions ${ }^{(1,3)}$.

\section{Case report}

A 98-year-old female was referred to our emergency room within 30 minutes of continuous chest pain and

Address for Correspondence: Çağlar Kaya, Trakya University Faculty of Medicine, Department of Cardiology, Edirne, Turkey Phone: +90 5556040604 e-mail: caglarkaya2626@gmail.com ORCID ID: orcid.org/0000-0002-2968-5352

Received: 16.02.2019 Accepted: 29.05.2019

Cite this article as: Kaya Ç, Zorkun CS, Yalta AK. How Old is Too Old? Observing A Centenarian After Primary PCI. EJCM 2019;7(2):101-103.

DOI: 10.32596/ejcm.galenos.2019.00057

${ }^{\circ}$ Copyright 2019 by Heart and Health Foundation of Turkey (TÜSAV) / E Journal of Cardiovascular Medicine published by Galenos Publishing House. 
rapidly progressive dyspnea. Sinus bradycardia (39 bpm) and hypotension $(85 / 55 \mathrm{mmHg})$ were noted at admission. Her electrocardiogram's showed signs of acute inferior and right ventricular myocardial infarction (Figure 1A-B). No pulmonary crackles and other physical examination abnormalities were observed. Echocardiography showed mild right ventricular dilatation, inferior wall akinesia, moderate mitral insufficiency, and $45 \%$ left ventricular ejection fraction (LVEF). Immediately after $300 \mathrm{mg}$ acetylsalicylic acid, $600 \mathrm{mg}$ clopidogrel and $5000 \mathrm{IU}$ unfractionated heparin load, a transvenous pacemaker was implanted and a coronary angiography was performed
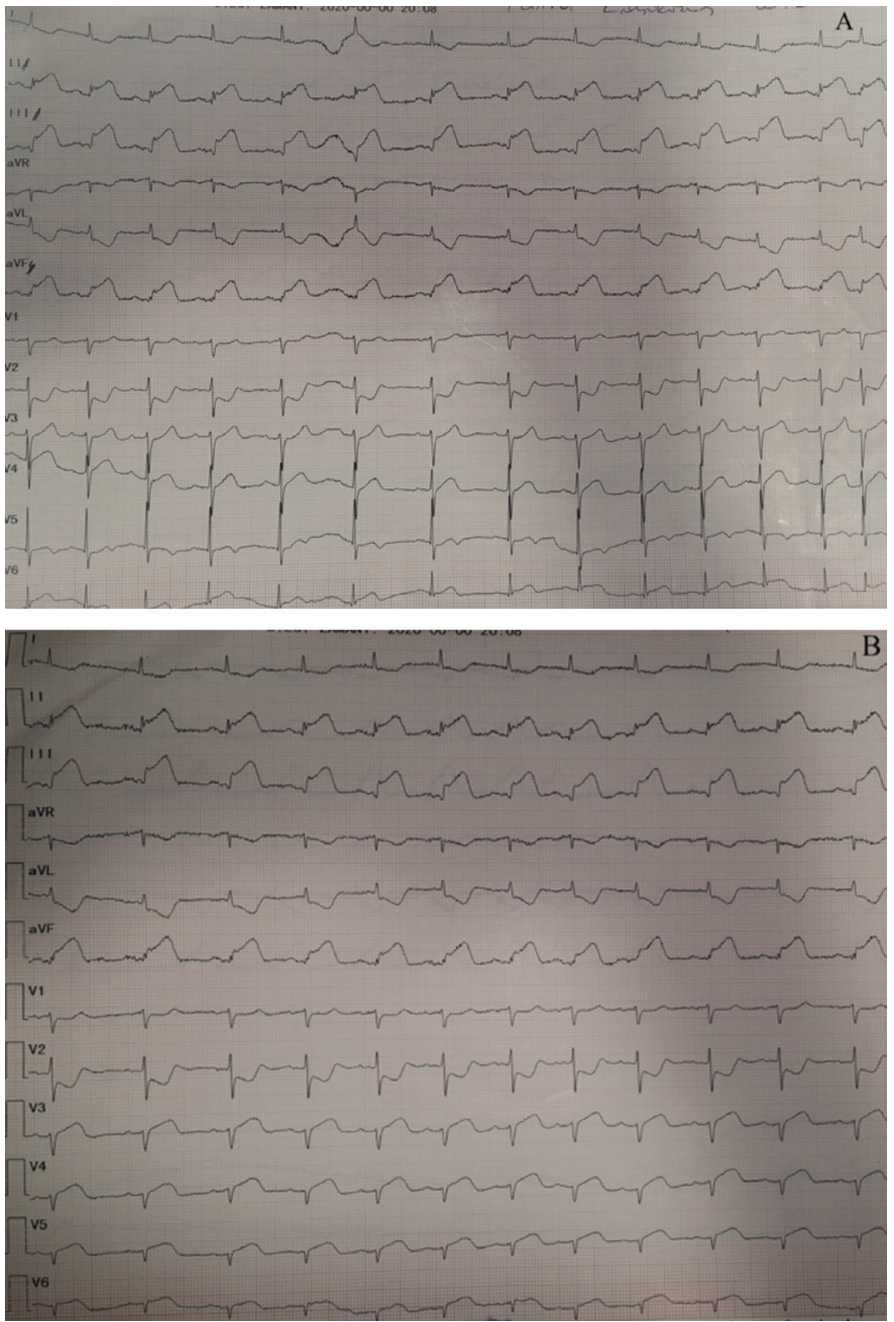

Figure 1. (A-B) Admission ECGs show an acute inferior and right ventricular myocardial infarction (A: left precordial leads, B: right precordial leads)
(Figure 2). At the same session, a drug eluting stent was implanted for proximal right coronary artery occlusion, and medical management decision made for borderline contralateral coronary lesions (Figure 2). She was complication free in-hospital course. The pacemaker removed on the second day and she discharged on the sixth day of hospital admission. In two-year follow-up at her 100 years of age; the patient was event-free, physically and mentally well with 54\% LVEF, a mild mitral regurgitation, and slight increase in kidney function tests. Her medical treatment was optimized and invited for regular clinical visits.

\section{Discussion}

People at their nineties (nonagenarians) are rapid growing proportions of patients treated with primary percutaneous coronary interventions in current clinical practice. Also, age-related physiological changes, disease progression, and frailty increase both potential benefits of mechanical revascularization and procedure-related adverse outcomes (e.g. access site bleeding and thrombotic

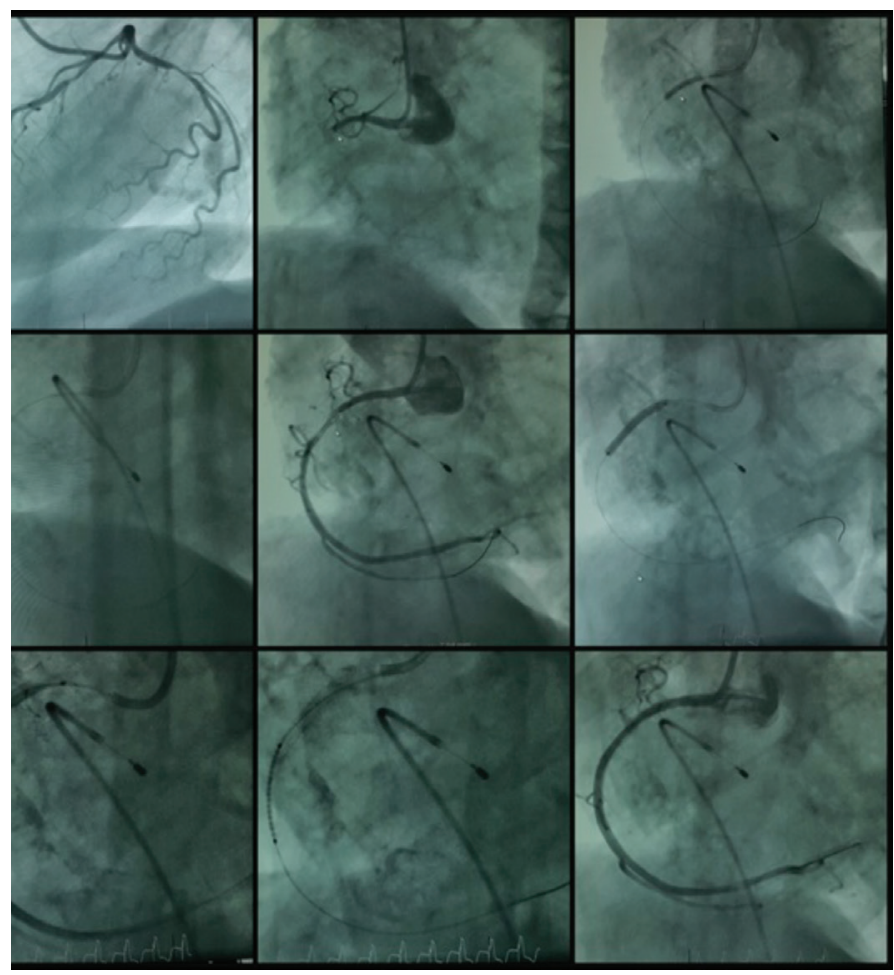

Figure 2. Coronary Angiography shows the lesions and stent implantation 
complications). We would like to stress it out that, timely invasive treatment in very elderly is better in acute setting in terms of short- and long-term outcomes. Including more patiaents at these ages to future randomized trials will help to improve our clinical experience in acute setting, broad current knowledge on this population, and might address advanced age-related problems in follow-up care. In this case report, we summarized our daily practice as performing coronary intervention in urgent settings in patients $>90$ years old along with mid to long term followup is safe but rare in the current literature.

\section{Ethics}

Informed Consent: Informed consent was obtained from the patient.

Peer-review: Externally and internally peer-reviewed.

\section{Authorship Contributions}

Surgical and Medical Practices: Ç.K., Concept: Ç.K., C.Z., Design: Ç.K., C.Z., Data Collection or
Processing: Ç.K., C.Z., A.K.Y., Analysis or Interpretation: Ç.K.,C.Z., A.K.Y., Literature Search: Ç.K., C.Z., A.K.Y., Writing: Ç.K., C.Z.

Conflict of Interest: No conflict of interest was declared by the authors.

Financial Disclosure: The authors declared that this study received no financial support.

\section{References}

1. Barron HV, Bowlby LJ, Breen T, Rogers WJ, Canto JG, Zhang Y, Tiefenbrunn AJ, Weaver WD. Use of reperfusion therapy for acute myocardial infarction in the United States: data from the National Registry of Myocardial Infarction 2. Circulation 1998;97:1150-6.

2. Galasso G, De Servi S, Savonitto S, Strisciuglio T, Piccolo R, Morici N, Murena E, Cavallini C, Petronio AS, Piscione F. Effect of an invasive strategy on outcome in patients $\geq 75$ years of age with non-ST-elevation acute coronary syndrome. Am J Cardiol 2015;115:576-80.

3. Mizuguchi Y, Hashimoto S, Yamada T, Taniguchi N, Nakajima S, Hata T, Takahashi A. Percutaneous coronary intervention for nonagenarian patients with ST-segment elevation myocardial infarction: Experience of a single Japanese center. J Cardiol 2016;67:331-4. 